\title{
LAS PAREJAS DE HECHO: ENTRE SOLUCIONES NACIONALES Y TENDENCIAS EUROPEAS*
}

\author{
SANDRA WinkLER \\ Profesora Titular de Derecho de Familia \\ en la Facultad de Derecho de la Universidad de Rijeka \\ E-mail: swinkler@pravri.hr
}

\begin{abstract}
RESUMEN: Entre las numerosas parejas que circulan por la Unión Europea, un número importante son parejas de hecho, si bien, los distintos ordenamientos jurídicos nacionales regulan de manera muy diferente las consecuencias jurídicas del ámbito de aplicación personal y los efectos patrimoniales de las parejas de hecho. El objetivo de este trabajo es analizar las diferentes regulaciones desde una perspectiva comparativa.

Dado que las parejas de hecho están excluidas del ámbito de aplicación del Reglamento sobre los efectos patrimoniales de las uniones registradas, las dificultades de interpretación y aplicación jurídica son muchas; implicando que su exclusión implica que la posición jurídica de las parejas de hecho transfronterizas sea bastante diferente y con menor protección que la posición jurídica de las uniones registradas transfronterizas, cuyas relaciones patrimoniales están cubiertas por el Reglamento sobre las consecuencias patrimoniales de una unión registrada, al igual que para los matrimonios transfronterizos les será de aplicación el Reglamento sobre los regímenes económicos matrimoniales, siendo ambos conocidos como los Reglamentos gemelos.
\end{abstract}

Palabras clave: pareja de hecho, pareja heterosexual, parejas del mismo sexo, modelos de familia, efectos patrimoniales, Derecho de familia.

ABSTRACT: Among the many couples circulating in the European Union, a significant number are de facto couples. Different national legal systems regulate the de facto couples' personal and property legal consequences in very different ways. The purpose of this paper is to investigate the differences in regulations from a comparative perspective.

Given that de facto couples are excluded from the scope of the Regulation on the Property Consequences of a Registered Partnership, the difficulties of legal interpretation and application are many. This exclusion also implies that the legal position of cross-border de facto couples is quite different and less protected than the legal position of cross-border couples whose property relations are covered by so-called the Twin Regulations, i.e. the Matrimonial 
Property Regulation or the Regulation on the Property Consequences of a Registered Partnership.

Keyword: de facto couples, heterosexual couples, same-sex couples, family formations, property regime, family law.

SUMARIO: I. INTRoducción. II. PaRejas de hecho: comparación de los sistemas juRídicos europeos. 2.1. Croacia y Eslovenia. 2.1.1. Croacia. 2.1.2. Eslovenia. 2.2. Italia. 2.3. España. 2.4. Lituania. 2.5. Similitudes y diferencias entre los sistemas juridicos comparados. III. PareJas de heCho en el Derecho de famila eUropeo. 3.1. El papel de los derechos humanos fundamentales en la europeización del derecho de familia. 3.2. Ámbito de aplicación: exclusión de las parejas de hecho. IV. OBSERVACIONES FINALES.

\section{INTRODUCCIÓN}

Las legislaciones nacionales de los Estados miembros de la UE difieren mucho en cuanto a la heterogeneidad de las soluciones jurídicas adoptadas en muchos ámbitos del Derecho de familia. El Derecho europeo tiene muy en cuenta a las familias, especialmente a las transfronterizas, y define un número cada vez mayor de aspectos transnacionales ${ }^{1}$. A este respecto, se han adoptado recientemente los llamados Reglamentos gemelos, que tratan de los regímenes patrimoniales de los cónyuges y de las parejas registradas. Sin embargo, en este capítulo no se analiza el ámbito de aplicación de ambos Reglamentos ${ }^{2}$. En su lugar, se presta atención a una cuestión excluida del ámbito de aplicación de dichos Reglamentos, centrándose específicamente en la regulación de las relaciones patrimoniales de las parejas de hecho transfronterizas.

Más adelante se intenta reconstruir las razones que han llevado al legislador europeo a excluir a las parejas de hecho de la lista de formaciones familiares cuyos perfiles patrimoniales son tratados por el Reglamento, especialmente en lo que respecta a las normas de conflicto y de procedimiento ${ }^{3}$. En primer lugar, es importante partir de un análisis comparativo de las normas jurídicas que regulan las parejas de hecho en diversos sistemas jurídicos europeos. Si combinamos las tendencias de migración y circulación de personas dentro (y fuera) de las fronteras de la UE y los constantes cambios sociales, llegamos a la conclusión de que es necesario comparar los sistemas jurídicos

1 * Traducido por Fátima Pérez Ferrer, profesora titular de Derecho penal y Ana María Pérez Vallejo, profesora titular de Derecho civil de la Universidad de Almería.

P. BRUNO, Le controversie familiari nell’Unione Europea. Regole, fattispecie, risposte, Giuffrè, Milán 2018.

2 Véase en detalle P. BRUNO, I regolamenti europei sui regimi patrimoniali dei coniugi e delle unioni registrate, Commento ai Regolamenti (UE) 24 giugno 2016, nn. 1103 e 1104 applicabili dal 29 gennaio 2019, Giuffrè Francis Lefebvre, Milano 2019; A. DUTTA; J. WEBER, Die Europäischen Güterrechtsverordnungen, Beck, München 2017.

3 Más información sobre las leyes nacionales y las tendencias europeas, véase en S. WINKLER, 'Imovinski odnosi u obitelji: nacionalna pravna rješenja i europski trendovi’ (2019) 1 Godišnjak Akademije pravnih znanosti Hrvatske X, pp. 447-467. 
extranjeros reflexionando sobre cómo (y si) las parejas de hecho transfronterizas encuentran protección jurídica ${ }^{4}$.

Históricamente, siempre se ha observado la necesidad de las personas de vivir en comunidad. La comunidad más estrecha se define comúnmente como la familia, que representa la sociedad primaria en la que los individuos reconocen el lugar y el refugio para satisfacer las necesidades más básicas de su vida, normalmente descritas como la intimidad en las relaciones interpersonales ${ }^{5}$. Sin embargo, no es sencillo clasificar todas las uniones que expresan esta necesidad íntima, sobre todo desde una perspectiva jurídica comparada ${ }^{6}$.

En general, las familias pueden adoptar la forma de matrimonio, parejas registradas y uniones de hecho ${ }^{7}$. Teniendo en cuenta que estas formas de vida familiar pueden ser tanto entre personas de distinto sexo como entre personas del mismo sexo, se puede concluir fácilmente lo diferente que es la interpretación de la idea de comunidad familiar y su protección jurídica en cada sistema nacional de la Unión Europea. El artículo 8 del CEDH protege claramente el derecho a la vida privada y familiar de toda persona. Sin embargo, hay que recordar que el mismo Convenio también subraya que cada país conserva su propia autonomía para regular jurídicamente las formaciones familiares capaces de proteger este derecho humano fundamental ${ }^{8}$.

En este punto se plantean cuestiones de interés: ¿La protección del derecho a la vida familiar significa que las diferentes formaciones familiares deben ser tratadas de la misma manera, o significa que se debe ofrecer a cada una de ellas la base sobre la que se puede proteger la vida familiar respetando la diversidad estructural de las mismas?.

Un análisis comparativo de estos fenómenos es de gran ayuda para comprender el alcance de esta cuestión ${ }^{9}$. Más concretamente, la diversidad de formaciones familiares varía inevitablemente en función de la amplitud de la interpretación del concepto de familia. Las diferencias de enfoque son evidentes ${ }^{10}$. De hecho, algunos sistemas jurídicos reconocen

4 Más información en <https://ec.europa.eu/eurostat/documents/3217494/7089681/KS-04-15-567-EN-N.pdf> consultado el 10.03.2021.

5 El término sociedad natural (società naturale) se utiliza, por ejemplo, en la Constitución italiana en el artículo 29. Véase C. M. BIANCA, La Famiglia, 2.1., Diritto civile, 5a ed., Giuffrè, Milán 2014, pp. 2 y ss.

6 J. M. SCHERPE, 'The legal status of cohabitants - Requirements for legal recognition' in K. BOELE-WOELKI (ed.), Common Core and Better Law in European family Law, Intersentia, Antwerpen - Oxford 2005, pp. 283 et seq.; B. VERSCHRAEGEN, 'The right to private life and family life, the right to marry and to found a family, and the prohibition of discrimination' in K. BOELE-WOELKI, A. FUCHS (eds.), Legal Recognition of Same-Sex Couples in Europe, In-tersentia, Antwerpen - Oxford - New York 2003, pp. 194 et seq.

7 Véase R. GARETTO, 'The Impact of Multicultural Issues on the Notion of «Family Member «' (2019) Zbornik znanstvenih razprav LXXIX letnik, 2019, pp. 7 y ss.

8 El Convenio para la Protección de los Derechos Humanos y de las Libertades Fundamentales, en su artículo 8(2), establece para los Estados que "No podrá haber injerencia de la autoridad pública en el ejercicio de este derecho, sino en tanto en cuanto esta injerencia esté prevista por la ley y constituya una medida que, en una sociedad democrática, sea necesaria para la seguridad nacional, la seguridad pública, el bienestar económico del país, la defensa del orden y la prevención del delito, la protección de la salud o de la moral, o la protección de los derechos y las libertades de los demás.".

9 I. CURRY-SUMNER, All's well that ends registered?, The substantive and private international law aspects of non-marital registered relationships in Europe, Intersentia, Antwerpen - Oxford 2005.

10 S. PATTI, 'Modelli di famiglia e convivenza', S. PATTI, M. G. CUBEDDU (eds), en Introduzione al diritto della famiglia in Europa, Giuffrè, Milano 2008, p. 116. 
la importancia jurídica de todas las formaciones legales mencionadas anteriormente ${ }^{11}$, ya estén compuestas por parejas del sexo opuesto o del mismo sexo ${ }^{12}$. Por el contrario, otros sistemas sólo conceden protección a aquéllas que se caracterizan por unas formalidades precisas en cuanto a la fecha de nacimiento o de finalización ${ }^{13}$. En este sentido, hay que diferenciar además entre los sistemas jurídicos que reconocen derechos a todas las parejas, a las parejas heterosexuales únicamente o las que limitan el reconocimiento de efectos a las parejas del mismo sexo registradas. En esencia, hay sistemas jurídicos que reconocen a las uniones de hecho una relevancia jurídica limitada, presumiblemente por considerar que su esencia reside precisamente en su existencia fuera de un determinado marco jurídico.

Probar la existencia de estas uniones de hecho se considera complejo, dado que puede variar de una ley a otra. En ocasiones, estas uniones informales no se identifican como algo que requiera protección. Independientemente de estas cuestiones, el hecho es que incluso el legislador europeo ha dejado a las parejas de hecho fuera del ámbito de aplicación del Reglamento UE nº 2016/1004.

En el examen comparativo que se realiza a continuación, no sería posible considerar todos los sistemas jurídicos ${ }^{14}$. Por lo tanto, sólo se tratan algunos sistemas jurídicos europeos considerados interesantes por las soluciones jurídicas que ofrecen (o no ofrecen).

\section{PAREJAS DE HECHO: COMPARACIÓN DE LOS SISTEMAS JURÍDICOS EUROPEOS}

Rara vez se encuentra una definición teórica explícita de las uniones de hecho en los sistemas jurídicos, incluidas las leyes de los países examinados en este capítulo. Un eminente académico croata -la importancia de su observación va más allá de las fronteras nacionales- señaló que, desde la perspectiva de la teoría del derecho, no hay razón para una definición única de las uniones de hecho, ya que no todas las estructuras concebibles de la vida familiar en la sociedad pueden reducirse a un único modelo ${ }^{15}$.

Como ya se ha mencionado, el complejo fenómeno de las parejas de hecho y la heterogeneidad de los contextos sociales han dado lugar a diferentes soluciones en materia de derecho de familia a la hora de regular estas uniones en cada uno de los ordenamientos jurídicos europeos. En Europa, sólo un pequeño número de Estados no regula las uniones

11 D. HENRICH, 'Rechtsregeln fuer nichteheliches Zusammenleben - Zusammenfassung', en I. KROPPENBERG, D. SCHWAB, D. HENRICH, P. GOTTWALD, A. SPICKHOFF (eds.), Rechtsregeln für nichteheliches Zusammenleben, Gieseking, Bielefeld, 2009, pp. 329 y ss.

12 Se han realizado muchos esfuerzos para reconstruir un marco taxonómico de las formaciones familiares existentes en la UE. Véase: Informe sobre la recogida de datos Análisis metodológico y taxonómico, Roberto Garetto (ed.), 2019 disponible en $<$ https://www.euro-family.eu/documenti/news/psefs report data_2019.pdf $>$ consultado el 15.5.2021.

13 Con respecto a las parejas registradas, véase I. SCHWENZER, 'Convergence and diver-gence in the law on same-sex partnerships', en M. ANTOKOLSKAIA (ed), Convergence and Di-vergence of Family Law in Europe, Intersentia, Antwerpen - Oxford 2007, pp. 45 y ss; M. BOGDAN, 'Registered Partnerships and EC Law', en K. BOELE-WOELKI, A. FUCHS (eds), Legal Recognition of Same-Sex Couples in Europe, Intersentia, Antwerpen - Oxford - New York 2003, pp. 171 y ss.

14 Para obtener un informe preciso de cada Estado miembro de la UE, véase L. RUGGERI, I. KUNDA, S. WINKLER (eds), Family Property and Succession in EU Member States National Reports on the Collected Data, Sveučilište u Rijeci, Pravni fakultet, Rijeka 2019 disponible en $<$ https://www.euro-family.eu/documenti/news/psefs e book compressed.pdf> consultado el 15.5.2021.

15 Véase M. ALINČIĆ, 'Promjene u propisima o braku i drugim životnim zajednicama', en D. HRA-BAR (ed), Hrestomatija hrvatskoga obiteljskoga prava, Pravni fakultet Sveučilišta u Zagrebu, Zagreb 2010, p. 78. 
distintas del matrimonio de personas de distinto sexo. De hecho, la mayoría de los sistemas jurídicos reconocen la protección legal de las formaciones familiares distintas del matrimonio, favoreciendo el registro de dichas uniones, que pueden estar compuestas por personas del mismo o distinto sexo.

Se analizarán las soluciones que Croacia, Eslovenia, Italia, España y Lituania han adoptado en el ámbito de las parejas de hecho para presentar los diferentes enfoques y soluciones que adoptan los países.

\subsection{Croacia y Eslovenia}

En estos sistemas jurídicos se presta especial atención a los fenómenos socioculturales, que son la base de los cambios en el derecho de familia ${ }^{16}$. Este ha sido el caso, tanto en el pasado, bajo la influencia de orientaciones conceptuales que en Croacia y Eslovenia eran hasta cierto punto diferentes de las de la parte occidental de Europa, como en la actualidad, bajo la influencia de las tendencias europeas actuales. Como los lazos sociales representan una clara evidencia de la evolución de las costumbres, las uniones de hecho no pueden sino desempeñar un papel en el interés central de quienes se ocupan de estas cuestiones ${ }^{17}$.

Croacia y Eslovenia destacan por sus opciones relacionadas con la regulación de las uniones de hecho pero, sobre todo, por la importante evolución que ha sufrido y sigue sufriendo su regulación ${ }^{18}$. La convivencia de hecho entre un hombre y una mujer está reconocida en estos dos Estados desde hace varias décadas ${ }^{19}$. Además, aunque se implantó más tarde, tanto en Croacia como en Eslovenia, las uniones homosexuales también están legalmente reconocidas. Y si bien, han surgido diferencias en el enfoque de la cuestión, al final se puede llegar a una conclusión que es común a ambos sistemas jurídicos: tanto la legislación croata como la eslovena revelan que estos países siguen dando preferencia a la institución del matrimonio, que a menudo se toma como modelo para regular las uniones de hecho.

Es cierto que ambos Estados regulan la convivencia heterosexual; sin embargo, es igualmente cierto que la regulación es limitada, ya que se trata de uniones alternativas al matrimonio. Sólo las parejas de distinto sexo pueden contraer matrimonio si así lo prefieren. Ambos Estados también regulan las parejas del mismo sexo y reconocen la necesidad de ofrecer una mayor protección jurídica a quienes no pueden casarse actualmente. Por

16 Una reconstrucción detallada de la influencia que estas corrientes de pensamiento tuvieron en general en los antiguos países socialistas puede encontrarse también en M. MLADENOVIĆ, C. JESSEL-HOLST, 'The Family in post-socialist countries', en A. CHLOROS, M. RHEINSTEIN, M. A. GLENDON (eds), Enciclopedia Internacional de Derecho Comparado, vol. IV, Personas y Familia, Mohr Siebeck, Marti-nus Nijhoff Publishers, Tübingen, Leiden, Boston, 2007, c. 10, pp. 3 y ss.

17 Además, es bien sabido que los sistemas jurídicos considerados (croata y esloveno) han prestado especial atención al estudio comparativo de las leyes extranjeras; esto ha permitido una fácil circulación de diferentes modelos jurídicos y la aceptación de soluciones extranjeras (también de sistemas jurídicos no europeos). A este respecto, véase K. ZUPANČIČ, 'Izvenzakonska skupnost v primerjalnem pravu' (1987) Pravnik, 147 y ss.

18 Véase S. WINKLER, 'Le unioni di fatto nell〉Europa centro-orientale: esperienze a confronto', en G. GABRIELLI, S. PATTI, A. ZACCARIA, F. PADOVINI, M.G. CUBEDDU WIEDEMANN, S. TROIANO (eds), Famiglia e Succioni, II, Liber amicorum per Dieter Henrich, Giappichelli, Turín 2012, pp. 122 y ss.

19 Es necesario dar un paso atrás en la historia jurídica común y menos reciente de estos países. Véase D. HRABAR, 'Legal Status of Cohabitants in Croatia', en J. M. SCHERPE, N. YASSARI (eds), Die Rechtsstellung nichtehelicher Lebensgemeinschaften, Max Planck Institut für ausländisches und internationales Privatrecht, Mohr Siebeck, Tübingen 2005, pp. 399 y ss. 
tanto, no es casualidad que para las parejas homosexuales se establezcan normas más detalladas que las que se aplican a las parejas heterosexuales ${ }^{20}$.

\subsubsection{Croacia}

En el Derecho de Familia croata, no existe una definición teórica expresa de las uniones de hecho. A este respecto, en la doctrina croata se señala que no hay razón para que exista tal concepto, ya que todas las uniones no pueden reducirse a una única definición ${ }^{21}$. Sin embargo, las uniones de hecho pueden estar formadas por parejas de distinto sexo y por parejas del mismo sexo.

A pesar de la falta de una definición, es posible reconstruirla indirectamente analizando los elementos constitutivos que caracterizan a estas parejas ${ }^{22}$. Para empezar con las parejas heterosexuales, estas uniones de hecho, normalmente denominadas "convivencia extramatrimonial" (izvanbračne zajednice), están reguladas en el artículo 11 de la Ley de Familia croata ${ }^{23}$. Según esta Ley, la convivencia extramatrimonial se define generalmente como la comunidad de vida entre una mujer y un hombre, ambos solteros, que dura al menos tres años o menos cuando nace un hijo mutuo o si continúa con el matrimonio. Esta unión comienza y termina de manera totalmente informal.

Aunque estas uniones de hecho entre personas de distinto sexo están reguladas legalmente desde hace décadas ${ }^{24}$, sus requisitos previos se han modificado a lo largo de los años ${ }^{25}$. La más reciente Ley de Familia (2015), basada en gran medida en la anterior (2003), ofrece en su artículo 11 una lista exhaustiva de requisitos previos, entre otros, como se ha dicho, que se trate de una pareja heterosexual no casada, duración de al menos tres años de convivencia o menos tiempo cuando nazca un hijo mutuo o si continuó con el matrimonio. Requisitos que el intérprete tiene que evaluar para reconocer si una unión de hecho está o no reconocida en el ordenamiento jurídico croata.

Debido a la ausencia de cualquier tipo de formalidad de dicha convivencia, puede resultar complicado aplicar los criterios mencionados anteriormente. Esto es especialmente cierto en el caso del requisito de que la cohabitación dure tres años, ya que es difícil determinar el comienzo o el final exacto de una unión de hecho. Puede decirse que el legislador ofrece una definición exhaustiva, pero que, en ausencia de cualquier restricción

20 Véase S. WINKLER, arriba n. 18, p. 134.

21 Ver D. HRABAR, 'The property relations between spouses and non-marital partners in Croatian law' (1999) Marital Community and Property in European Comparison, 143 et seq.

22 M. BUKOVAC PUVAČA, I. KUNDA, S. WINKLER, D. VRBLJANAC, 'Croacia' en L. RUGGERI, I. KUNDA, S. WINKLER (eds. ), Family Property and Succession in EU Member States, National Reports on the Collected Data, Sveučilište u Rijeci, Pravni fakultet, Rijeka 2019, pp. 68-92<https://www.euro-f Obiteljski zakon, Narodne novine, $n^{\circ}$ 103/15, 98/19 y 47/20.amily.eu/doc. Acessed 15/01/2021.

23 Obiteljski zakon, Narodne novine, $n^{\circ} 103 / 15,98 / 19$ y 47/20.

24 Zakon o braku i porodičnim odnosima, Narodne novine, no 11/1978, 27/1978, 45/1989 y 59/1990. En los años 70, el legislador no ofreció ninguna definición para especificar qué convivencias merecían ser protegidas y cuáles no. Más concretamente, el artículo 12 de la Ley de Matrimonio y Relaciones Familiares establece que la obligación de manutención mutua y algunos otros derechos y deberes derivados del derecho de propiedad surgen de la unión extramatrimonial entre una mujer y un hombre. Salvo la mencionada diversidad de género de los miembros de la pareja, no se mencionaba la duración de la relación, ni el estatus de los miembros de la pareja, ni la existencia de hijos propios nacidos durante la relación.

25 Obiteljski zakon, Narodne novine, no 162/1998;, Obiteljski zakon, Narodne novine, $\mathrm{n}^{\circ}$ 116/03, 17/04, 136/04, 107/07, 57/11, 61/11, 25/13, 05/15; Obiteljski zakon, Narodne novine, $\mathrm{n}^{\circ}$ 75/2014, 83/2014 y 05/2015; Obiteljski zakon, Narodne novine, $\mathrm{n}^{\mathrm{o}}$ 103/15, 98/19 y 47/20. 
formal, está destinada a seguir siendo extremadamente vaga, es decir, sujeta a diversas interpretaciones de los tribunales ${ }^{26}$. La confusión aumenta aún más por el hecho de que, además de la definición contenida en la Ley, existen varias definiciones de las uniones de hecho en diversas leyes especiales; definiciones que a menudo chocan y permiten calificar de forma diferente la misma unión ${ }^{27}$. La razón por la que las uniones de hecho de personas de distinto sexo se incluyen en varias leyes es que el legislador les concede numerosos derechos. El artículo 11 de la Ley de Familia sólo establece los derechos que conciernen al derecho de familia, mientras que otras leyes regulan las consecuencias jurídicas en el ámbito de los derechos laborales, de pensión, fiscales, de sucesión, etc. Por tanto, aunque esta técnica normativa es objeto de crítica por parte de la doctrina, estas leyes suelen dictar también la calificación de estas formaciones de hecho (aunque no hacen lo mismo con otras, como el matrimonio ${ }^{28}$. Las relaciones patrimoniales de las parejas heterosexuales de hecho se regulan únicamente en la Ley de Familia, por lo que el problema señalado anteriormente no se plantea aquí. Estas consecuencias patrimoniales se regulan en el apartado 2 del artículo 11 de la Ley de Familia. Además, se regulan de forma muy clara: remitiendo in totum a las normas que regulan los regímenes matrimoniales ${ }^{29}$.

El ordenamiento jurídico croata también regula las uniones entre personas del mismo sexo $^{30}$. Sin embargo, el legislador optó por regular dichas uniones mediante una ley distinta a la Ley de Familia ${ }^{31}$.

Anteriormente, las parejas homosexuales de hecho estaban reguladas por la Ley de Uniones del Mismo Sexo (2003) ${ }^{32}$, pero desde 2014 está en vigor la nueva Ley de Uniones de Vida del Mismo Sexo, que introdujo la posibilidad de registrar dichas uniones $^{33}$. Más concretamente, la legislación pertinente reconoce dos tipos de uniones del mismo sexo: las sujetas a registro y las totalmente informales. Estas últimas parecen ser similares a las uniones de hecho formadas por personas de distinto sexo. Sin embargo, existen algunas distinciones interesantes en cuanto a los requisitos que el legislador establece respecto a la existencia de las uniones de hecho de las personas del mismo sexo. El artículo 3 de la Ley de uniones de hecho entre personas del mismo sexo (2014) establece que "la unión vitalicia informal es la unión de dos personas del mismo sexo, que no han inscrito su unión ante un registro, que ha durado al menos tres años y que cumple los requisitos para la inscripción válida de una unión vitalicia desde el principio”.

26 Para una visión detallada, véase N. LUCIĆ, Izvanbračna zajednica i pravna sigurnost, Narodne novine, Zagreb 2020.

27 D. HRABAR, 'Izvanbračna zajednica - neka otvorena pitanja' (2010) Hrvatska Pravna Revija 2, pp. 43 y ss.

28 M. BUKOVAC-PUVAČA, S. WINKLER, 'Nasljednopravni učinci izvanbračnih zajednica i neformalnih životnih partnerstava' (2021) IX Zbornik radova, Deveti međunarodni naučni skup Dani porodičnog prava 9, pp. 129-154.

29 A este respecto, véase A. KORAĆ GRAOVAC, 'Imovinski odnosi', en M. ALINČIĆ, D. HRABAR, D. JAKOVAC-LOZIĆ, A- KORAĆ GRAOVAC, Obiteljsko pravo, Narodne novine, Zagreb 2007, pp. 495-533; V. BELAJ, 'Stjecanje imovine (vlasništva) u bračnoj i izvanbračnoj zajednici' (2005) 26 Zbornik Pravnog fakulteta Sveučilišta u Rijeci 1, p. 346.

30 Mientras que, para una amplia reconstrucción de las uniones de hecho entre personas del mismo sexo antes de la entrada en vigor de la Ley croata de 2003, véase N. HLAČA, 'Zajednica života osoba istog spola' (1992) 42 Zbornik Pravnog Fakulteta u Zagrebu 4, pp. 447 y ss.

31 Cfr. R. PACIA, S. WINKLER, 'Invisible Minorities within Extramarital Unions - Comparison of Different Solutions Provided by the Family Laws', en N. BODIROGA-VUKOBRAT, G.G. SANDER, S. BARIĆ (eds), Unsichtbare Minderheiten. Minorías invisibles, Verlag dr. Kovač, Hamburgo 2013, pp. 57-93.

32 Zakon o istospolnim zajednicama, Narodne novine, No. 116/2003.

33 Zakon o životnom partnerstvu osoba istog spola, Narodne novine, No. 92/2014. 
La primera diferencia con respecto a las uniones heterosexuales de hecho es que el reconocimiento de una unión homosexual de hecho está sujeto al cumplimiento de los requisitos de validez de la inscripción. Estos requisitos son: (i) los miembros de la pareja deben ser mayores de edad (mayoría de edad); (ii) los miembros de la pareja deben estar en plena posesión de sus facultades o, si son incapaces de actuar con respecto a los actos relativos a su estado personal, se requiere la aprobación de su tutor; (iii) no han registrado la unión con otra pareja ni han contraído matrimonio y (iv) no son parientes por consanguinidad o adopción. Es evidente que algunos de los requisitos mencionados siguen claramente algunos de los impedimentos matrimoniales.

Aunque existen estas diferencias en los requisitos para las uniones de hecho homosexuales en comparación con las heterosexuales, lo que tienen en común es la ausencia de formalidad. Por lo tanto, con respecto a las parejas de hecho homosexuales se plantea el mismo problema a la hora de probar su existencia. Por último, en lo que respecta a sus consecuencias jurídicas -en virtud del artículo 4 de la Ley de parejas de hecho del mismo sexo (2014), de forma similar a lo que el legislador establece en la Ley de la familia-, estas consecuencias son similares a las previstas para las parejas registradas del mismo sexo. Para las consecuencias jurídicas no previstas en la propia Ley de parejas de hecho del mismo sexo, se hace referencia a otras leyes especiales. Es evidente la existencia de una doble vía, en la que se yuxtaponen las dos formaciones familiares formales (matrimonio para personas de distinto sexo y registro para personas del mismo sexo) con las dos versiones informales de estas relaciones, que, a pesar de su vaguedad, si se reconocen, dan lugar a importantes consecuencias jurídicas. Se trata de consecuencias patrimoniales que no encuentran protección en el ámbito supranacional, a pesar del elevado número de parejas de hecho en Europa.

\subsubsection{Eslovenia}

A diferencia del derecho croata, el derecho esloveno no ha sufrido muchas reformas del derecho de familia. Desde la década de 1970 y hasta 2019, ha estado en vigor la misma ley, es decir, la Ley de Matrimonio y Relaciones Familiares ${ }^{34}$. El nuevo Código de Familia entró en vigor el 15 de abril de $2019^{35}$. Cabe señalar que la reciente reforma del derecho de familia esloveno no ha supuesto ningún cambio significativo en la norma que define las uniones extramatrimoniales en la legislación eslovena. Según el artículo 4 del nuevo Código de Familia, "una unión extramatrimonial es un acuerdo de convivencia a largo plazo entre un hombre y una mujer que no están casados y para los que no hay motivos para que el matrimonio sea inválido. Dicha unión tendrá las mismas consecuencias jurídicas en virtud de este Código y que les conciernen como si hubieran contraído matrimonio; en otros ámbitos del derecho, dicha unión tendrá consecuencias jurídicas si la ley así lo establece" ${ }^{\prime 6}$. A diferencia de la solución prevista en la ley croata, aquí la definición se concibe de manera diferente. En efecto, se de-fine como una unión vitalicia entre una

34 Zakon o zakonski zvezi in družinskih razmerjih, OJ SRS, No. 15/76 con otras modificaciones. K. ZUPANČIČ, Family Law, Uradni list Republike Slovenije, Ljubljana 1999, p. 97.

35 Družinski zakonik, OJ RS, No. 15/2017 con nuevas modificaciones. Sobre la reforma del derecho de familia, véanse las observaciones introductorias de K. ZUPANČIČ, B. NOVAK, V. ŽNIDARŠIČ SKUBIC, M. KONČINAPETERNEL, Reforma del derecho de familia, Uradni list, Liubliana 2009, pp. 17 y ss.

36 Para un análisis preciso del artículo 4, véase B. NOVAK (ed), Comentario al Código de la Familia, Uradni list RS, Ljubljana 2019. 
mujer y un hombre no casados, sin embargo, otros elementos son diferentes. El Código de Familia esloveno (2019) no hace referencia a un período específico de convivencia, ni este período puede acortarse en presencia de otras condiciones como el nacimiento de un hijo ${ }^{37}$. Además, el legislador esloveno subraya claramente que la validez de dicha unión está sujeta a la ausencia de cualquier impedimento matrimonial. Así pues, se observa que el legislador esloveno ha dado forma a la regulación de la unión extramatrimonial entre un hombre y una mujer inspirándose claramente en la institución del matrimonio ${ }^{38}$. Al igual que en el derecho croata, la ausencia absoluta de toda formalidad caracteriza tanto el inicio como el fin de la relación de hecho, creando los mismos problemas para probar su existencia ${ }^{39}$. Por otra parte, la prueba de su existencia es esencial para reconocer las consecuencias jurídicas de dichas uniones de hecho. También en este caso, como se ha observado anteriormente, el legislador ha optado por una remisión completa a las normas jurídicas del matrimonio para todas las consecuencias jurídicas (incluidas las patrimoniales) derivadas de dichas uniones de hecho ${ }^{40}$.

El ordenamiento jurídico esloveno también regula las uniones entre personas del mismo sexo. El reconocimiento legal de las uniones del mismo sexo se introdujo por primera vez en una ley distinta: la Ley de Registro de Uniones del Mismo Sexo (Zakon o registraciji istospolne partnerske skupnosti) de $2005^{41}$. Esta ley fue sustituida en 2016 por la Ley de Unión Civil (Zakon o partnerski zvezi), que entró en vigor en 201742. Al igual que las disposiciones de la ley croata, la normativa eslovena contempla dos formaciones diferentes compuestas por parejas del mismo sexo: la unión civil "formal" y la "informal". Esto significa que la ley permite el registro de dicha unión, pero también reconoce los efectos legales para las parejas de hecho (no registradas). La unión "informal" se califica como una comunidad de vida duradera entre personas del mismo sexo que no han registrado su unión si no existen causas de nulidad de su unión. Las normas jurídicas que rigen el matrimonio "se aplican mutatis mutandis a las uniones civiles" 43 , lo que es válido para las "formales" y las "informales". En cuanto a las consecuencias jurídicas derivadas de una unión civil de hecho y en el caso de una unión civil registrada, son por tanto idénticas en cuanto a las consecuencias patrimoniales derivadas del matrimonio ${ }^{44}$.

\subsection{Italia}

En la legislación italiana, el término familia de hecho (famiglia di fatto) se utiliza para aquellas uniones que, a pesar de no estar formalizadas, tienen una estructura similar a

37 Ibid. p. 44.

38 Véase S. WINKLER, arriba 18, p. 132.

39 Una parte de la doctrina eslovena critica el nuevo proyecto de reforma del derecho de familia precisamente porque no prevé el registro de las parejas heterosexuales de hecho. A este respecto, véase B. ZADRAVEC, 'Pomanjkljivosti Družinskega zakonika' (25.02.2010) 29/930, Pravna Praksa 8, pp. 11 y ss.; V. ŽNIDARŠIČ SKUBIC, 'Zunajzakonska skupnost - nekateri (aktualni) problemi' (2007) XXXIII Podjetje in delo 1, pp. 205 y ss.

40 Ver B. NOVAK, arriba n. 36, p. 45.

41 Zakon o registraciji istospolne partnerske skupnosti, Uradni List RS n. 65/2005. En la literatura, véase B. NOVAK, 'Eslovenia ha regulado legalmente las parejas del mismo sexo' (2006) FamRZ, p. 600.

42 .Zakon o partnerski zvezi, Uradni list RS, No. 33/16

43 Véase F. DOUGAN, 'Slovenia', en L. RUGGERI, I. KUNDA, S. WINKLER (eds), Family Property and Succession in EU Member States, National Reports on the Collected Data, Sveučilište u Rijeci, Pravni fakultet, Rijeka 2019, p. $593<$ https://www.euro-family.eu/documenti/news/psefs e book_compressed.pdf $>$.

44 Ibid. p. 594. 
la familia basada en el matrimonio ${ }^{45}$. Antes de 2016, el ordenamiento jurídico italiano no preveía ni una legislación específica ni una definición legal de dichas uniones ${ }^{46}$. Sin embargo, una serie de disposiciones legales que definen aspectos jurídicos individuales derivados de las mencionadas "situaciones vitales" aumentaron notablemente en los últimos años antes de la reforma de la familia italiana de hecho ${ }^{47}$. Se puede concluir que se superó la resistencia a regular las uniones de hecho de personas de distinto sexo. Del mismo modo, se ha demostrado que ha llegado el momento de reconocer legalmente el registro de las parejas del mismo sexo. En efecto, la Ley n ${ }^{\circ} 76$ de 20 de mayo de 2016 introdujo la unión civil en el ordenamiento jurídico italiano y, al mismo tiempo, reguló la dicha convivencia. Tras la promulgación de esta Ley de 2016, la legislación italiana reconoce dos uniones de hecho diferentes (en el sentido de la convivencia), dependiendo de si surgieron antes o después de $2016^{48}$. La distinción entre las parejas anteriores y posteriores a la promulgación de la Ley de 2016 es relevante porque las parejas de hecho pueden tener una protección diferente en función del momento de su creación. Hay que tener en cuenta que antes de 2016 no existía una legislación específica que regulara este tipo de uniones. En consecuencia, no existía una regulación legal sobre los criterios para su existencia ni se determinaban las consecuencias jurídicas de dichas uniones ${ }^{49}$.

En cuanto a las parejas heterosexuales no casadas, existen dos elementos constitutivos de estas uniones. El primero es de carácter objetivo y está representado por una convivencia estable de los miembros de la pareja. El segundo elemento tiene una base subjetiva caracterizada por la affectio maritalis, es decir, la participación mutua de un miembro de la pareja en la vida del otro, expresando afecto, solidaridad y apoyo económico. Antes de 2016, parecía posible ampliar la noción de pareja de hecho también a aquellas convivencias en las que uno o ambos miembros de la pareja no eran solteros. Esto era consecuencia de una normativa anterior del derecho de familia italiano, que implicaba necesariamente una separación previa de años entre los dos cónyuges antes del divorcio. Los cónyuges separados seguían estando casados; estaban legalmente obligados a esperar los plazos para divorciarse legalmente, mientras que, emocionalmente, la unión matrimonial ya había terminado. Después de 2016, la noción del artículo 1 de la Ley de

45 V. BONANNO, 'Regímenes matrimoniales y convivencia de hecho en el derecho europeo e italiano', en J. KRAMBERGER ŠKERL, L. RUGGERI, F. G. VITERBO (eds), Case studies and best practices analysis to enhance eu family and succession law. Documento de trabajo, (2019) Quaderni degli Annali della Facoltà Giuridica dell'Università di Camerino 3, pp. 19-30.

46 Para una reconstrucción de las normas sobre las uniones de hecho en la legislación italiana antes de 2016, véase R. MAZZARIOL, Convivenze di fatto e autonomia privata: il contratto di convivenza, Jovene editore, Napoli 2018. Véase también M.G. CUBEDDU WIEDEMANN, 'Rechtsregeln für nichteheliches Zusammenleben in Italien', en I. KROPPENBERG, D. SCHWAB, D. HENRICH, P. GOTTWALD, A. SPICKHOFF (eds), Rechtsregeln für nichteheliches Zusammenleben, Beitrage zum europäischen Familienrecht, Gieseking, Bielefeld 2009, pp. 119 y ss. Recientemente, R. GARETTO, M. GIOBBI, A. MAGNI, T. PERTOT, E. SGUBIN, M. V. MACCARI, 'Italia', en L. RUGGERI, I. KUNDA, S. WINKLER (eds), Family Property and Succession in EU Member States, National Reports on the Collected Data, Sveučilište u Rijeci, Pravni fakultet, Rijeka 2019, pp. 356-390< $\underline{\text { https:// }}$ www.euro-family.eu/documenti/news/psefs_e_book_compressed.pdf $>$ consultado el 15.5.2021.

47 Sobre las diferentes uniones familiares ver más en G. PERLINGIERI, 'Interferencias entre la unión civil y el matrimonio. Pluralismo familiar y unidad de valores normativos' (2018) Civil Law Review 1, p. 101.

48 R. GARETTO, M. GIOBBI, A. MAGNI, T. PERTOT, E. SGUBIN, M. V. MACCARI, arriba 46, p. 361.

49 No obstante, la jurisprudencia realizó un gran esfuerzo que, junto con soluciones jurídicas aisladas que protegían ciertos aspectos de dichas uniones, proporcionaron una forma fragmentada de marco jurídico. A este respecto, véase R. PACIA, S. WINKLER, supra 31, pp. 63-83. 
2016 establece claramente que uno de los requisitos necesarios para que exista dicha unión es la libre condición de las personas implicadas.

En ausencia de la comunión de vida que expresa el animus típico de la vida conyugal (affectio maritalis), las uniones de hecho -aunque denoten una dimensión afectiva y una solidaridad recíproca- no pueden ser reconocidas como formaciones familiares protegidas por el Derecho de familia ${ }^{50}$. Obviamente, estas relaciones se caracterizan siempre por la ausencia de toda formalidad: comienzan y terminan fuera de cualquier marco formal.

En cuanto a las consecuencias jurídicas relativas a las parejas heterosexuales no casadas nacidas después de 2016, pueden celebrar un contrato de convivencia para regular sus relaciones patrimoniales ${ }^{51}$. Sensu contrario, significa que si no celebran dicho contrato, no existe un marco jurídico preciso que regule sus bienes patrimoniales ${ }^{52}$.

Las parejas del mismo sexo también están reguladas en el ordenamiento jurídico italiano desde la reforma de 2016. La nueva legislación introdujo la posibilidad de que las parejas homosexuales registren su unión. Además, la regulación legal de las parejas de hecho incluye a las parejas heterosexuales y homosexuales por igual. Una forma de pareja del mismo sexo registrada (unione civile) tiene los mismos derechos personales y patrimoniales que los prescritos para una relación matrimonial, aunque en este caso no exista un deber de fidelidad matrimonial. Así, en virtud del artículo 13 de la Ley n 76 de 2016, el régimen patrimonial de la unión civil de parejas del mismo sexo sigue las mismas reglas que las aplicables al matrimonio. En efecto, la comunidad de bienes es el régimen jurídico aplicable, salvo que las partes acuerden otra cosa. Si se necesitan normas adicionales, se remite a las disposiciones del Código Civil relativas a la comunidad de bienes, la separación de bienes, la comunidad de bienes convencional y el fondo patrimonial ${ }^{53}$. Lo que difiere de los sistemas esloveno y croata analizados anteriormente es que en Italia las parejas de hecho no reciben el mismo trato que el matrimonio o las uniones civiles.

\subsection{España}

El marco jurídico que la legislación española establece para las parejas de hecho compuestas por personas del mismo o distinto sexo es extremadamente articulado y complejo ${ }^{54}$. Incluye una combinación de diferentes normas de derecho civil dentro del sistema jurídico español, dependiendo de si se aplica el Código Civil como fuente principal o si las normas especiales pueden representar una fuente jurídica distinta y predominante sobre la nacional $1^{55}$. De la misma manera, a lo que se ha observado hasta ahora, España también reconoce

50 Podría ser el caso de uniones con un importante apoyo financiero o religioso mutuo, sobre todo entre las personas mayores.

51 Véase L. RUGGERI, S. WINKLER, 'Neka pitanja o imovinskim odnosima bračnih drugova u hrvatskom i talijanskom obiteljskom pravu' (2019) 40 Zbornik Pravnog fakulteta Sveučilišta u Rijeci, 1, pp. 167-200.

52 Véase R. PACIA, S. WINKLER, arriba 31, p. 78.

53 R. GARETTO, M. GIOBBI, A. MAGNI, T. PERTOT, E. SGUBIN, M. V. MACCARI, arriba 46, pp. 365-370.

54 Para un análisis preciso, véase A. M. PÉREZ VALLEJO, M. J. CAZORLA GONZÁLEZ, 'Spain' en L. RUGGERI, I. KUNDA, S. WINKLER (eds), Family Property and Succession in EU Member States, National Reports on the Collected Data, Sveučilište u Rijeci, Pravni fakultet, Rijeka 2019, pp. 616 y ss. <https://www.euro-family.eu/ documenti/news/psefs e book compressed.pdf $>$ consultado el 15.5.2021.

55 Véase C. GONZÁLEZ BEILFUSS, 'Relación patrimonial entre cónyuges - ESPAÑA' $<$ http://ceflonline.net/ property-relations-reports-by-jurisdiction/> p. 2, consultado el 30.5.2021. La autora en su informe ofrece una nota 
esencialmente tres formaciones familiares: el matrimonio entre personas de distinto sexo o entre personas del mismo sexo, las parejas de hecho registradas (formalizadas) entre personas del mismo o distinto sexo y las uniones de hecho entre personas del mismo y distinto sexo. Sería imposible reconstruir el complicadísimo sistema español, cuya peculiaridad se percibe al compararlo con otros. Baste decir que todas las formaciones familiares enumeradas están presentes, si no en todas, al menos en algunos territorios.

En particular, en cuanto a las uniones de hecho, hay que destacar la ausencia de una disposición general y común. En otras palabras, no existe una definición única de las uniones de hecho en el ámbito de la legislación nacional. Como en el pasado en el ordenamiento jurídico italiano (antes de la Ley de 2016), la calificación de las parejas de hecho depende prácticamente del esfuerzo de la jurisprudencia y la doctrina. Así, la definición de la unión gira en torno al carácter de estabilidad, que tiende a representar la prueba de la comunión de vida al compartir intereses, necesidades íntimas y un proyecto de vida común.

Es muy interesante observar que, en el caso de estas uniones de hecho, cuyo carácter es totalmente informal, corresponde en primer lugar a los miembros de la pareja proteger sus intereses (especialmente su patrimonio) mediante acuerdos especiales. Si no lo hacen, las autoridades judiciales decidirán las consecuencias patrimoniales en cada caso. A este respecto, el Tribunal Supremo español es muy claro al subrayar que estas uniones de hecho no deben equipararse al matrimonio ${ }^{56}$.

En este sentido, vemos una diferencia con lo observado anteriormente en otros ordenamientos jurídicos, donde se tiende a equiparar las formaciones familiares, creando "duplicidades". La interpretación de la jurisprudencia española es interesante y aceptable ya que evita la existencia de formaciones familiares equiparables en cuanto a los efectos jurídicos que producen, aunque su naturaleza jurídica sea indudablemente diferente. Por ello, ni siquiera es fácil afirmar cuáles son las consecuencias jurídicas de las uniones de hecho. Esto es especialmente cierto si pensamos en los distintos regímenes patrimoniales existentes en el ordenamiento jurídico español, ya que varían de un lugar a otro. Corresponde al juez identificar tanto la existencia de una unión de hecho como sus posibles consecuencias jurídicas.

\subsection{Lituania}

Básicamente, el ordenamiento jurídico lituano no regula ninguna otra forma de vida familiar salvo el matrimonio entre un hombre y una mujer ${ }^{57}$; aunque, para ser más precisos, además del matrimonio, el Código Civil lituano reconoce un tipo más de unión: la pareja

introductoria muy clara y precisa: «Al ser el derecho español un ordenamiento jurídico no unificado, no existe un derecho español uniforme sobre la relación patrimonial entre los cónyuges. Este informe se ocupa únicamente de las normas del engañosamente denominado «Derecho civil común», que coexisten con las normas de los llamados «Derechos civiles forales» (Cataluña, Baleares, Aragón, Navarra, País Vasco y Galicia).» Además, subraya, «qué ley se aplica a una determinada pareja es una cuestión de conflicto de leyes (...)».

56 Véase A. M. PÉREZ VALLEJO, M. J. CAZORLA GONZÁLEZ, supra 54, p. 617. Los autores se remiten expresamente a la Sentencia del Pleno 611/2005, de 12 septiembre de 2005 (Tol 725211), "Como reitera el Tribunal Supremo (TS) en su sentencia de 12 de septiembre de 2005: 'la unión de hecho es una in-stitución que nada tiene que ver con el matrimonio, aunque ambos formen parte del derecho de familia"'.

57 Véase A. LIMANTE, T. CHOCHRIN, 'Lituania', en L. RUGGERI, I. KUNDA, S. WINKLER (eds), Family Property and Succession in EU Member States, National Reports on the Collected Da-ta, Sveučilište u Rijeci, Pravni 
registrada. Ésta sólo puede ser una unión entre parejas de distinto $\mathrm{sexo}^{58}$. Las relaciones patrimoniales de una pareja registrada del sexo opuesto se regulan en los artículos 3.2293.235 del Código Civil lituano. Las condiciones establecidas por el Código Civil lituano para la existencia de una pareja registrada son muy similares a las del matrimonio. Los miembros de la pareja deben ser mayores de edad, poseer plena capacidad jurídica, ser de sexo opuesto y no estar casados, y no pueden ser parientes consanguíneos. Por lo tanto, al igual que en otros países ya analizados, el registro de una pareja entre personas del sexo opuesto sólo se permite entre adultos, lo que significa que el registro de una pareja entre menores no está permitido. Además, la relación de pareja tiene que ser verificada: para que sea posible, los miembros de la pareja deben haber vivido juntos durante al menos un año ${ }^{59}$.

Sin embargo, las parejas de hecho no pueden registrarse en la práctica de momento, debido a la falta de leyes aplicables. Las parejas de hecho no están reguladas expresamente por la ley, pero encuentran protección en la jurisprudencia ${ }^{60}$. A este respecto, es interesante recordar la jurisprudencia del Tribunal Supremo de Lituania, que destaca que, en el caso de las parejas que llevan un estilo de vida similar al de una pareja casada, "sus relaciones patrimoniales se consideran un "acuerdo de convivencia"

En cuanto a las parejas del mismo sexo, el derecho de familia lituano no reconoce jurídicamente ninguna comunión de vida entre personas del mismo sexo, por lo que pasa a formar parte del grupo minoritario de sistemas jurídicos europeos que no conceden protección jurídica a las parejas del mismo sexo ${ }^{62}$.

\subsection{Similitudes y diferencias entre los sistemas jurídicos comparados}

Aunque las legislaciones española y lituana difieren sustancialmente en su enfoque del reconocimiento (o no reconocimiento) de las uniones de personas del mismo sexo, tienen en común la forma en que tratan a las parejas de hecho. Es decir, al desmarcarlas del matrimonio o de las parejas de hecho registradas, Lituania y España reconocen una

fakultet, Rijeka 2019, pp. 408-426 < https://www.euro-family.eu/documenti/news/psefs e book_compressed.pdf $>$ consultado el 15.5.2021.

58 A este respecto, véase G. SAGATYS, 'The Concept of Family in Lithuanian Law' (2010) 1 Juris-prudencija Mokslo darbų žurnalas, 184, disponible en < $<$ https://ojs.mruni.eu/ojs/jurisprudence/article/view/1094/1047> consultado el 20.5.2021.

59 Véase I. MICHAILOVIENE, 'Informal relationships - LITHUANIA', pp. 1-36 <http://ceflonline.net/informalrelationships-reports-by-jurisdiction/> consultado el 30.5.2021. En efecto, citando: "Aunque el Código Civil lituano está en vigor (...) (desde 2001) siguen faltando normas que regulen las relaciones entre los convivientes, porque no se ha adoptado ninguna ley especial, ya que dicha incoherencia y la falta de claridad jurídica influyen evidentemente en las disputas legales dentro de la sociedad y en los diferentes enfoques dentro de la jurisprudencia. Las citadas disposiciones del Código Civil lituano (art. 3.229-3.235) no se han aplicado en la práctica; sin embargo, tampoco se han suprimido (...)".

60 Ibid, p. 1-3. En cuanto a las consecuencias patrimoniales, el autor señala que "teniendo en cuenta que el art. 3.229-3.235 del Código Civil lituano no se aplican en la práctica, los tribunales suelen basarse en las disposiciones generales al examinar los conflictos materiales entre personas no casadas, como las disposiciones del Libro IV, "Derecho material", del Código Civil lituano sobre la división de los bienes comunes entre copropietarios, así como las disposiciones del Libro VI, "Derecho de Obligaciones", del Código Civil lituano en relación con un acuerdo sobre actividades conjuntas (una sociedad) en la creación de una propiedad conjunta-parcial".

61 A. LIMANTE, T. CHOCHRIN, supra 57, p. 418. Una de las decisiones más recientes a las que se refieren los autores es la sentencia del Tribunal Supremo de 28 de marzo de 2011, n 3K-3-1343.

62 Véase G. SAGATYS, supra 58, pp. 193-194. 
característica fáctica que distingue a las parejas de hecho de otras formaciones familiares, dejándolas fuera del marco legal.

El mismo enfoque (no regular las parejas de hecho) se aplicó en el pasado en la legislación italiana, que, con la legislación de 2016, cambió radicalmente el marco jurídico preexistente. Esto se hizo, por un lado, definiendo las parejas heterosexuales de hecho y, por otro, introduciendo una regulación de "doble vía" de estas uniones: las parejas surgidas antes de la entrada en vigor de la ley tendrán unos efectos jurídicos determinados; las posteriores, otros. Sin embargo, se ha dado un paso importante si se compara con los países minoritarios que no reconocen la protección legal de las parejas del mismo sexo ${ }^{63}$. Italia está a medio camino, más en línea con Croacia y Eslovenia, que, al establecer normas muy similares, ofrecen un grado de protección jurídica a todas las formaciones familiares, ya sean parejas heterosexuales u homosexuales, e incluso van más allá al equiparar los efectos jurídicos de las uniones de hecho con las formales. Ciertamente, esto ofrece una amplia protección, pero, sin embargo, plantea la cuestión de por qué la diversidad intrínseca de la naturaleza jurídica de estas formaciones familiares queda completamente desdibujada en cuanto a las consecuencias jurídicas.

\section{LAS PAREJAS DE HECHO EN EL DERECHO DE FAMILIA EUROPEO}

El Derecho de familia en la UE no está armonizado a nivel de normas sustantivas. Sin embargo, tanto bajo la influencia de los derechos fundamentales como del derecho derivado de la UE, el derecho de familia está experimentando un proceso de europeización que no deja intacto ni siquiera el derecho sustantivo ${ }^{64}$. Esta armonización indirecta se produce a pesar de que el legislador europeo no es competente para establecer normas en el plano sustantivo, que sigue siendo prerrogativa exclusiva de los Estados miembros. Las soluciones de derecho sustantivo se exploran sobre todo desde un punto de vista comparado para descubrir las diferencias y similitudes que son útiles para una adecuada comprensión e interpretación de los distintos institutos jurídicos del derecho de familia ${ }^{65}$. Esto es útil para proporcionar la mejor protección posible, especialmente a nivel supranacional, a las situaciones familiares con elementos de naturaleza transfronteriza ${ }^{66}$.

63 Ver: R. GARETTO (ed.), Informe sobre la recogida de datos Análisis metodológico y taxonómico, 2019 disponible en $<$ https://www.euro-family.eu/documenti/news/psefs_report data_2019.pdf $>$. En la publicación se puede encontrar toda la información relativa al reconocimiento de las diferentes formaciones familiares en cada Estado miembro de la UE.

64 El derecho de familia, que durante mucho tiempo ha permanecido en un segundo plano, está experimentando un importante proceso de armonización a nivel europeo. En los últimos años, los esfuerzos de la ciencia jurídica en este sentido se están intensificando rápidamente. Ex plurimis: M. ANTOKOLSKAIA, Harmonisation of Family Law in Europe: A Historical Perspective, A Tale of two Millennia, Intersentia, Antwerpen - Oxford 2006; M. T. MEULDERS-KLEIN, ¿¿Hacia un derecho de familia europeo uniforme? Un enfoque político. General conclusions', en M. ANTOKOLSKAIA (ed), Convergence and Divergence of Family Law in Europe, Intersentia, Antwerpen - Oxford 2007, pp. 271 y ss.; S. PATTI, M. G. CUBEDDU (eds), Introduzione al diritto della famiglia in Europa, Giuffrè, Milano 2008; K. BOELE-WOELKI, 'What comparative family law should entail', en K. BOELE-WOELKI (ed.), Debates sobre el derecho de familia en todo el mundo en los albores del siglo XXI, Intersentia, Ant-werpen - Oxford 2009, pp. 3 y ss.

65 D. HENRICH, 'Entwicklungen des Familienrechts in Ost un West' (2010) FamRZ, 2010, 5, pp. 333 y ss.

66 En cuanto a los regímenes de propiedad, véase M. J. CAZORLA GONZÁLEZ, M. GIOBBI, J. KRAMBERGER ŠKERL, L. RUGGERI, S. WINKLER (eds), Property Relations of Cross-Border Couples in the European Union, 
El creciente número de familias compuestas por personas de diferentes nacionalidades o que viven en países distintos al de su nacionalidad hace necesaria la creación de normas comunes en el ámbito del derecho de familia. Nacen nuevas familias que luego terminan, dejando muchas cuestiones jurídicas sin resolver. Por ello, el legislador europeo ha realizado importantes avances en la armonización de las normas de Derecho internacional privado ${ }^{67}$. Sin embargo, aunque estas soluciones ofrecen un marco más homogéneo, al identificar normas comunes para la identificación del derecho (nacional) aplicable, persiste una cierta diversidad entre los derechos nacionales en el plano material. El derecho sustantivo nacional participa mucho menos en el proceso de europeización. Por lo tanto, el punto de partida de cualquier intento de analizar y reconstruir ${ }^{68}$ el fenómeno de la europeización del Derecho de familia es la comparación de diferentes sistemas legales de familia europea, lo cual hemos hecho en la primera parte del capítulo.

\subsection{El papel de los derechos humanos fundamentales en la europeización del derecho de familia}

Llegados a este punto, hay que hacer una premisa. El término "Derecho de familia europeo" se utiliza con frecuencia en la literatura ${ }^{69}$. Sin embargo, a menudo las delimitaciones de lo que abarca este término son poco claras. Existen dos niveles diferentes: El derecho de familia europeo "en sentido amplio" y el derecho de familia europeo "en sentido estricto".

El Derecho de familia europeo en sentido amplio consiste en un conjunto de normas resultantes del trabajo de tres organizaciones distintas: el Consejo de Europa, la Conferencia de La Haya de Derecho Internacional Privado y la Unión Europea ${ }^{70}$. En cambio, cuando hablamos de Derecho de familia europeo en sentido estricto, nos referimos a las nuevas directrices legislativas y jurisprudenciales que la Unión Europea ha empezado a establecer recientemente. En efecto, el modo de proceder de las instituciones europeas es muy fragmentario y cauteloso. Fragmentaria porque a menudo sólo se regulan algunos

Edizioni Scientifiche Italiane, Nápoles 2020, disponible en: <https://www.euro-family.eu/documenti/news/esi en psefsbook.pdf $>$ consultado el 13.5.2021.

67 F.D. BUSNELLI, M.C. VITUCCI, 'European Family Foundations' (2013) I Rivista di diritto civile, pp. 777 y ss.

68 Hay una fuente (soft law) muy importante en el proceso de europeización del derecho de familia que no procede de Bruselas: los Principios sobre el Derecho de Familia Europeo (PEFL) elaborados por la Comisión de Derecho de Familia Europeo (CEFL). Esta Comisión está formada por expertos jurídicos de muchos países europeos que se reúnen en Utrecht desde 2001 para estudiar el derecho de familia en los países europeos con el fin de encontrar soluciones comunes. Los resultados de las investigaciones realizadas por la CEFL, al igual que las realizadas por otros grupos de estudiosos en otras áreas del derecho privado, convergen en "principios" que son la expresión de las tendencias actuales del derecho de familia en Europa.

Los legisladores nacionales individuales, aunque no están obligados a seguir estos principios, los tienen en cuenta; algunas reformas recientes del derecho de familia en los sistemas jurídicos nacionales individuales se han visto influidas por ellos. Para un análisis en profundidad de los trabajos de la Comisión de Derecho de Familia Europeo, véase el sitio web oficial $<\underline{\text { www.ceflonline.net }}>$ (consultado el 20.5.2021), donde se pueden encontrar los cuestionarios, los informes nacionales individuales y los Principios resultantes relativos a los temas individuales tratados hasta ahora, en su totalidad y en varias lenguas.

69 K. BOELE-WOELKI, 'Obiteljsko pravo u Europi: prošlost, sadašnjost, budućnost' en I. KUNDA (ed), Obitelj i djeca: europska očekivanja i nacionalna stvarnost, Pravni fakultet u Rijeci, Hrvatska udruga za poredbeno pravo, Rijeka 2014, pp. 17-28.

70 Véase I. MAJSTOROVIĆ, 'Obiteljsko pravo kao različitost u jedinstvu: Europska unija i Hrvatska', en A. KORAĆ GRAOVAC, I. MAJSTOROVIĆ (eds), Europsko obiteljsko pravo, Narodne novine, Zagreb 2013, pp. 1-24. I. ŠIMOVIĆ, I. ĆURIĆ, 'Europska unija i obiteljsko pravo. Međunarodnoprivatnopravni, procesnopravni i materijalnopravni aspekti’ (2015) 22 Ljetopis socijalnog rada 2, pp. 163-189. 
aspectos concretos de la materia en ausencia de un marco normativo más general. Cauteloso porque, teniendo en cuenta la competencia exclusiva de los legisladores nacionales para legislar sobre los aspectos sustantivos del derecho de familia, el legislador europeo se cuida de no sobrepasar estos límites ${ }^{71}$.

Por lo tanto, es necesario comenzar analizando el papel que los derechos humanos fundamentales han desempeñado en el desarrollo del derecho de familia y, en particular, en la lenta aparición del derecho de familia europeo ${ }^{72}$.

Empezando con una perspectiva amplia, dentro del CEDH, un papel importante en este proceso tiene el artículo 8 que garantiza el derecho a la vida privada y familiar, así como el artículo 14 que prohíbe cualquier forma de discriminación. La jurisprudencia del TEDH sugiere claramente que el concepto de vida privada y familiar es muy amplio. En particular, según el apartado 1 del artículo 8 del CEDH, una familia no consiste exclusivamente en una célula hombre-mujer de la que resulta una relación matrimonial ${ }^{73}$. Por el contrario, otro tipo de familia también puede encontrarse en otra forma de relación afectiva. En efecto, el TEDH reconoce que una relación afectiva de personas que conviven, también en una forma de familia de hecho, si dicha convivencia es una unión lo suficientemente estable como para permitir identificar el animus y el corpus. Estos distinguen las diferentes uniones de vida y dan origen a un proyecto familiar. Además, al aplicar los principios de no discriminación a los que se refiere el artículo 14 del CEDH, el TEDH dijo que cada Estado del Consejo Europeo debe tomar medidas razonables en orden a evitar la discriminación de las parejas del mismo sexo, es decir, tomar medidas razonables y proporcionales al objetivo que representa un equilibrio entre el interés público y el privado ${ }^{74}$.

Asimismo, debe hacerse referencia al artículo 7 y al artículo 9 de la Carta de los Derechos Fundamentales de la Unión Europea ${ }^{75}$. En particular, la Carta, además de reconocer el derecho al respeto de la vida privada y familiar (artículo 7), prohíbe cualquier forma de discriminación basada (entre otras cosas) en la orientación sexual (artículo 21). Además, el artículo 9 de la Carta establece el derecho a contraer matrimonio y el derecho a fundar una familia. Más concretamente, establece que "el derecho a contraer matrimonio y el derecho a fundar una familia se garantizan de conformidad con las leyes nacionales que regulan el ejercicio de estos derechos". En cuanto al mencionado artículo 9, cabe destacar dos hechos: la falta de referencia al sexo de los cónyuges y la necesidad de distinguir el derecho al matrimonio del derecho a fundar una familia. En otras palabras, La Carta de los Derechos Fundamentales, en lo que respecta a la noción de familia, remite a la tradición jurídica y a la cultura de cada país. Esto significa que el concepto de familia

71 Véase más en S. WINKLER, 'Il diritto di famiglia', en G.A. BENACCHIO, F. CASUCCI (eds), Temi e Istituti di Diritto Privato dell〉Unione Europea, Giappichelli, Turín 2017, pp. 293 y ss.

72 Para un análisis detallado de la regulación de las parejas del mismo sexo a la luz de los derechos humanos fundamentales, véase A. KORAĆ GRAOVAC, 'Ljudska prava i pravno uređenje istospolnih zajednica u domaćem zakonodavstvu', en D. HRABAR (ed), Hrestomatija hrvatskoga obiteljskog prava, Pravni fakultet Sveučilišta u Zagrebu, Zagreb 2010, pp. 235 y ss.

73 Véase G. SAGATYS, arriba 58, p. 187.

74 Recientemente, véase la decisión del TEDH del 14 de diciembre de 2017, en el caso Orlandi y otros contra Italia, solicitud no 26431/12.

75 Carta de los Derechos Fundamentales de la Unión Europea, DO C 326 de 26.10.2012, pp. 391-407. En la bibliografía véase A. KORAĆ GRAOVAC, 'Povelja o fundamentnim pravima Europske unie i obiteljsko pravo', en A. KORAĆ GRAOVAC, I. MAJSTOROVIĆ (eds), Europsko obiteljsko pravo, Narodne novine, Zagreb 2013, pp. 25-51. 
(y también su alcance) puede variar sustancialmente. Además, se puede concluir -en lo que respecta al tema que nos ocupa- que no existe ninguna obligación para el legislador nacional de reconocer las convivencias que no puedan vincularse con el concepto de familia de ese país concreto.

Debido a la coordinación sistemática de la Carta Europea y el CEDH, que fue posible gracias al Tratado de Lisboa, se ha producido la correspondencia de estas fuentes jurídicas en lo que respecta a los derechos fundamentales de las personas en las relaciones jurídicas familiares para lograr la igualdad de términos y abordar la importancia de ambos. Las diversidades sociales, culturales y jurídicas de las soluciones nacionales en materia de derecho de familia llevan a concluir que corresponde al legislador decidir si regula o no las uniones de hecho.

Es interesante detenerse un momento en la jurisprudencia del Tribunal de Justicia, cuyas sentencias se aplican directamente a los ordenamientos jurídicos internos. Los jueces del TJUE se han pronunciado, hasta hace poco, únicamente sobre cuestiones relacionadas con los derechos de libre circulación y los derechos sociales de los trabajadores (y de sus familiares) y la prohibición de la discriminación por razón de sexo u orientación sexual; eso sí, siempre en el contexto de los derechos sociales y laborales de las personas. Sin embargo, una señal de cambio proviene de la reciente sentencia en el caso Coman $^{76}$. El caso se refería al reconocimiento del matrimonio entre personas del mismo sexo (a efectos del derecho migratorio), y no a las uniones de hecho, pero es muy significativo en el contexto de la europeización del derecho de familia. Esta sentencia deja claro que la cuestión del estatuto personal, así como las consecuencias jurídicas derivadas de una relación familiar, es una cuestión de derecho nacional y que el derecho de la UE no interfiere en este ámbito. Más concretamente, subraya que los Estados miembros deciden de forma independiente si regulan o no una determinada comunidad de vida (en este caso, el matrimonio entre personas del mismo sexo). Sin embargo, la sentencia también señala, y esto es muy significativo, que los derechos concedidos a determinadas personas por el Derecho de la UE no pueden ser restringidos por el Derecho nacional.

Dejando de lado la jurisprudencia y mirando en un sentido más amplio, se puede concluir que, aunque no existe un marco normativo europeo común en el ámbito del derecho de familia, las tendencias supranacionales tienen un impacto en los sistemas nacionales individuales, a los que se anima a repensar sus normas ${ }^{77}$. Este replanteamiento no debe dar lugar a una distorsión de la tradición y la cultura jurídica de cada país, que se refleja, en particular, en el derecho de familia. Sin embargo, representa el curso normal de la evolución de las cosas en una sociedad mucho más móvil e integrada que, también en el derecho, se ve inevitablemente afectada por las consecuencias de los profundos cam-

76 Asunto C-673/16, Relu Adrian Coman y otros contra Inspectoratul General pentru Imigrări y Ministerul Afacerilor Interne, EU:C:2018:385. Véase en la bibliografía M. NI SHUILLEABHAIN, 'Cross-Border (Non-)Recognition of Marriage and Registered Partnership: Free Movement and EU Private International Law', en J.M. SCHERPE, E. BARGELLI (eds), The Interaction between Family Law, Succession Law and Private International Law, Adapting to change, Intersentia, Cambridge-Antwerp-Chicago 2021, p. 16.

77 Se han realizado grandes análisis comparativos, especialmente en los últimos veinte años. A este respecto, le invitamos a consultar los numerosos estudios realizados por la Comisión de Derecho de Familia Europeo. Véase

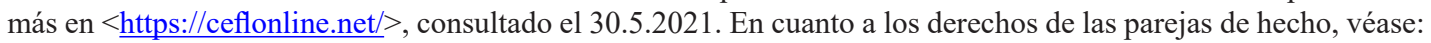
K. BOELE-WOELKI, F. FERRAND, C. GONZALEZ BEILFUSS, M. JÄNTERÄ-JAREBORG, N. LOWE, D. MARTINY, V. TODOROVA, Principles of European Family Law Regarding Property, Maintenance and Succession Rights of Couples in de facto Unions, Intersentia, Cambridge 2019. 
bios culturales y sociológicos que se han producido en las últimas décadas. El derecho de familia, más que ningún otro derecho, refleja estos grandes cambios.

\section{2. Ámbito de aplicación de la normativa: exclusión de las parejas de hecho}

Ya se ha observado que, aunque los Reglamentos gemelos no pretenden aproximarse a las normas sustantivas del Derecho de familia, su importancia es fundamental para el proceso de europeización del Derecho de familia. No sólo establecen normas comunes de procedimiento y de conflicto de leyes, sino que también tienen el mérito de motivar la comparación de los diferentes sistemas nacionales de Derecho de familia, en particular, en lo que respecta a las cuestiones que tratan. En efecto, el reciente Reglamento sobre los regímenes matrimoniales y el Reglamento sobre las consecuencias patrimoniales de las uniones registradas ofrecen un marco normativo, resultante de la cooperación reforzada de un número relevante de Estados miembros de la UE en el ámbito de la competencia, la ley aplicable, el reconocimiento y la ejecución de las decisiones sobre los regímenes matrimoniales y las consecuencias patrimoniales de las uniones registradas, respectivamente ${ }^{78}$.

Sin embargo, aparte de las dificultades derivadas de la heterogeneidad de las normas sobre regímenes patrimoniales familiares establecidas en los distintos Estados, una cuestión central era la de qué unidades familiares se regularían en la futura normativa, es decir, si el legislador debía regular únicamente las relaciones entre los cónyuges o también las que surgen en otras formas de familia, como las parejas registradas y las parejas de hecho.

Al final, el legislador optó por regular las relaciones entre cónyuges (en un reglamento) y entre parejas registradas (en otro reglamento).

Dado el variopinto marco jurídico descrito anteriormente respecto a algunos sistemas jurídicos, hay que tener en cuenta que puede haber muchas combinaciones de familia (del mismo sexo, de distinto sexo o de ambos) de parejas registradas y/o de hecho que consistan en personas de distinto sexo o del mismo sexo. Además, algunos sistemas de parejas registradas están abiertos a todas ellas, otros países sólo reconocen legalmente las parejas del mismo sexo, mientras que otros reservan la institución de la pareja sólo a las parejas del sexo opuesto. No es de extrañar que en 2015 se abandonara la idea de dictar normas vinculantes para todos los ordenamientos jurídicos europeos. Por ello, dieciocho países de la UE optaron por recurrir a la cooperación reforzada ${ }^{79}$. Ello condujo a la adopción de los Reglamentos gemelos.

Estos Reglamentos, que entraron en vigor el 29 de enero de 2019, no tocan el derecho sustantivo. Así, en el considerando 17 del Reglamento sobre los bienes matrimoniales, se indica expresamente que no existe una definición de matrimonio, remitiéndose para ello a las legislaciones nacionales individuales. Del mismo modo, en el considerando 17 del Reglamento sobre las consecuencias patrimoniales de las uniones registradas se aclara que "la "unión registrada" debe definirse aquí únicamente a efectos del presente

78 P. LAGARDE, 'Reglamentos 2016/1103 y 1104, de 24 de junio de 2016, sobre los regímenes matrimoniales y sobre el régimen patrimonial de las parejas de hecho registradas' (2016) Rivista di diritto internazionale privato e processuale, pp. 680 y ss.

79 Así, Alemania, Austria, Bélgica, Bulgaria, Chipre, Croacia, Eslovenia, España, Finlandia, Francia, Grecia, Italia, Luxemburgo, Malta, Países Bajos, Portugal, República Checa y Suecia han expresado su deseo de establecer una cooperación reforzada en el ámbito de los regímenes de propiedad de las parejas internacionales. 
Reglamento. El contenido real del concepto debe volver a definirse en las legislaciones nacionales de los Estados miembros. Nada de lo dispuesto en el presente Reglamento debe obligar a un Estado miembro cuya legislación no contemple la institución de la unión registrada a preverla en su legislación nacional"80.

Sin embargo, una cosa es cierta: las parejas de hecho quedan excluidas del ámbito de aplicación de ambos Reglamentos ${ }^{81}$. Entre los Reglamentos gemelos, parecería más lógico añadir las parejas de hecho al contenido del Reglamento sobre las consecuencias patrimoniales de la unión registrada. Sin embargo, este último establece claramente la exclusión de estas formaciones familiares de la lista de parejas transfronterizas que encuentran protección jurídica en esta fuente de Derecho derivado de la UE. En particular, el apartado 1 del artículo 1 del Reglamento sobre los efectos patrimoniales de las uniones registradas establece expresamente que "el presente Reglamento se aplicará a las cuestiones relativas a los efectos patrimoniales de las uniones registradas". Para comprender mejor esta disposición, el artículo debe leerse en conjunción con el considerando 16. Además, debe tenerse en cuenta la letra a) del apartado 1 del artículo 3 del Reglamento sobre los efectos patrimoniales de las uniones registradas: "se entiende por pareja registrada el régimen de vida en común de dos personas previsto por la ley, cuyo registro es obligatorio en virtud de la misma y que cumple las formalidades legales exigidas por dicha ley para su creación".

Si se ponen en común las disposiciones pertinentes, es evidente que la legislación europea (en concreto, el Reglamento sobre las consecuencias patrimoniales de las uniones registradas) se limita a regular determinadas cuestiones relativas a las consecuencias patrimoniales de las parejas registradas, dejando a los distintos ordenamientos jurídicos nacionales un amplio margen de interpretación. Ya se ha dicho que una pareja registrada puede significar muchas cosas, o rectius puede ofrecer protección jurídica a parejas compuestas de diferentes maneras, pero todas unidas por un requisito formal: el registro ${ }^{82}$. Por el contrario, al subrayar la gran diversidad de normas nacionales sobre las "uniones de hecho", el legislador europeo optó por no abarcarlas. Una de sus consecuencias es que la posición jurídica de las parejas de hecho transfronterizas es muy diferente de la de las parejas transfronterizas cuyas relaciones patrimoniales se rigen por los Reglamentos gemelos (es decir, las parejas casadas o registradas). En efecto, estas parejas son invisibles y carecen de protección jurídica a nivel europeo. Esta invisibilidad a nivel supranacional

80 Véase A. R. BENOT, ‘Article 3 Definitions', en I. VIARENGO, P. FRANZINA (eds), The EU Regulations on the Property Regimes of International Couples, A Commentary, Edward Elgar Publishing, Cheltenham 2020, p. 35.

81 Véase el considerando 16 del Reglamento sobre las consecuencias patrimoniales de las uniones registradas, que dice: «La forma en que las legislaciones de los Estados miembros contemplan las formas de unión distintas del matrimonio difiere de un Estado a otro, y conviene distinguir entre las parejas cuya unión está sancionada institucionalmente por el registro de su unión ante una autoridad pública y las parejas en situación de convivencia de hecho. Aunque algunos Estados miembros prevén estas uniones de hecho, deben considerarse por separado de las parejas registradas, que tienen un carácter oficial que permite tener en cuenta sus características específicas y establecer normas al respecto en la legislación de la Unión. Para garantizar el buen funcionamiento del mercado interior, es necesario eliminar los obstáculos a la libre circulación de las personas que han constituido una pareja registrada, en particular los que crean dificultades a estas parejas en la administración y la división de sus bienes. Para alcanzar estos objetivos, el presente Reglamento debe reunir las disposiciones relativas a la competencia, la ley aplicable, el reconocimiento o, en su caso, la aceptación, la fuerza ejecutiva y la ejecución de las resoluciones, los documentos públicos y las transacciones judiciales".

82 A. R. BENOT, 'Article 1 Scope', en I. VIARENGO, P. FRANZINA (eds), The EU Regulations on the Property Regimes of International Couples, A Commentary, Edward Elgar Publishing, Chel-tenham 2020, p. 20. 
crea bastantes problemas ${ }^{83}$. Podemos aceptar plenamente la posición de quienes no reconocen la necesidad de proteger jurídicamente estas formaciones familiares o de quienes consideran que el reconocimiento de las parejas a las que se aplica la legislación europea en ausencia de requisitos previos formales resulta muy complejo e incierto. Sin embargo, también hay que tener en cuenta que en muchos sistemas jurídicos, el derecho de familia reserva más de una consecuencia jurídica a la multitud de uniones informales. Tomemos, por ejemplo, las uniones de hecho de personas de distinto sexo en el derecho croata. En el derecho croata, las uniones de hecho son prácticamente equivalentes al matrimonio en cuanto a los efectos jurídicos patrimoniales. Sin embargo, si existe un elemento de transnacionalidad, dichas uniones quedan sin regulación. Sus efectos patrimoniales, en presencia de elementos transfronterizos, se dejan en manos de las normas individuales de derecho internacional privado establecidas por cada Estado, con la consiguiente ampliación de las posibles situaciones que perjudican la libre circulación de personas.

\section{OBSERVACIONES FINALES}

El panorama jurídico europeo es tan variado que aún no existen características uniformes capaces de crear el mínimo común denominador referido a las uniones de hecho. El punto más crítico que se desprende de la comparación de las legislaciones nacionales es la necesidad de un reconocimiento legal en todos los países europeos. En la actualidad, algunos sistemas decidieron regular sólo las uniones de hecho compuestas por parejas del sexo opuesto, otros sólo las uniones del mismo sexo y el tercero de ambos. Sin una regulación legal clara, las personas que viven en este tipo de uniones podrían considerarse invisibles. También hay que tener en cuenta que a menudo hay debilidades detrás de la protección establecida en el ordenamiento nacional único, especialmente en lo que se refiere a la circulación de los ciudadanos y al reconocimiento de su estatus familiar. La adopción del Reglamento representa ciertamente un paso adelante. Sin embargo, es un paso tímido e incierto que muestra una vez más los límites del enfoque inevitablemente fragmentado del legislador europeo en el ámbito del derecho de familia. Las parejas de hecho son la prueba palpable de lo complejo que es estudiar y aplicar el derecho de familia en la UE. No obstante, su situación debe tenerse en cuenta, ya que el número de parejas que viven en régimen de pareja no registrada no es desdeñable entre las parejas transfronterizas.

83 Véase R. PACIA, S. WINKLER, arriba 31, p. 65. T. KRUGER, 'Partners limping across borders', en I. KUNDA (ed), Obitelj i djeca: europska očekivanja i nacionalna stvarnost, Pravni fakultet u Rijeci, Hrvatska udruga za poredbeno pravo, Rijeka 2014, pp. 185 y ss. 